\title{
Grain boundaries in Nd-Fe-B-based alloys
}

\author{
B. B. Straumal ${ }^{\dagger, 1,2,3}$, A. A. Mazilkin ${ }^{1,3}$, S. G. Protasova ${ }^{1}$, A. B. Straumal ${ }^{1,4}$, B. Baretzky ${ }^{3}$ \\ †'straumal@issp.ac.ru
}

\author{
${ }^{1}$ Institute of Solid State Physics, RAS, 2 Academician Ossipyan St., Chernogolovka, 142432, Russia \\ ${ }^{2}$ Chernogolovka Scientific Center, RAS, 9 Lesnaya St., Chernogolovka, 142432, Russia \\ ${ }^{3}$ Karlsruhe Institute of Technology (KIT), Institute of Nanotechnology, \\ Hermann-von-Helmholtz-Platz 1, Eggenstein-Leopoldshafen, 76344, Germany \\ ${ }^{4}$ National University of Science and Technology “MISiS”, 4 Leninskii Av., Moscow, 119049, Russia
}

\begin{abstract}
In this review we consider the microstructure of grain boundaries (GBs) in the Nd-Fe-B-based alloys for permanent magnets. It is generally accepted that the unique hard magnetic properties of such alloys are controlled by the thin layers of a Nd-rich phase in $\mathrm{Nd}_{2} \mathrm{Fe}_{14} \mathrm{~B} / \mathrm{Nd}_{2} \mathrm{Fe}_{14} \mathrm{~B}$ GBs. These GB layers ensure the magnetic isolation of $\mathrm{Nd}_{2} \mathrm{Fe}_{14} \mathrm{~B}$ grains from each other. It is generally supposed that such GB layers contain metallic $\mathrm{Nd}$ or Nd-rich intermetallic compounds. However, the commercial $\mathrm{Nd}-\mathrm{Fe}$-B-based permanent magnets frequently contain the tangible amount of neodymium oxide $\mathrm{Nd}_{2} \mathrm{O}_{3}$ in the triple junctions between $\mathrm{Nd}_{2} \mathrm{Fe}_{14} \mathrm{~B}$ grains. In this review we show that oxide layers are also present in the GBs in Nd-Fe-B-based permanent magnets. The Nd-based phase in GBs can form continous layers between $\mathrm{Nd}_{2} \mathrm{Fe}_{14} \mathrm{~B}$ grains (this case is called complete wetting). It corresponds to the zero contact angle between $\mathrm{GB}$ and Nd-rich phase. If the contact angle is non-zero, the Nd-based phase forms the chain of particles in the GB. In turn, if the GB between these particles is "dry", this case is called the incomplete wetting. If the GB between the Nd-rich particles contains the thin layer of a Nd-rich phase (either metallic or oxide), this case is called the pseudo-incomplete (or pseudo-partial) GB wetting.
\end{abstract}

Keywords: permanent magnets, coercivity, Nd-Fe-B alloys, oxide layers, grain boundaries, thin layers, wetting.

\section{Introduction}

Since their discovery in 1980-ies, the Nd-Fe-B-based alloys remain the best ones among other permanent magnets [1-7]. They possess the highest magnetic energy product $\left(B H_{c}\right)_{\max }\left(B\right.$ being the saturation magnetization, and $H_{c}$ being the coercivity). Their $B$ value now almost reached its theoretical limit thanks to the favorable combination of magnetic characteristics (saturation magnetization, and uniaxial anisotropy constant) of $\mathrm{Nd}_{2} \mathrm{Fe}_{14} \mathrm{~B}$ intermetallic compound and careful alloying of the Nd-Fe-B-based permanent magnets. However, the coercivity is still far away from its possible maximum. $H_{c}$ increases if the domain walls have a limited mobility, and cannot penetrate through the grain boundary (GB) from one $\mathrm{Nd}_{2} \mathrm{Fe}_{14} \mathrm{~B}$ grain to another when the external magnetic field changes its direction and value $[4,5]$.

Usually, the Nd-rich phase in GBs is responsible for this "magnetic isolation" or decoupling of $\mathrm{Nd}_{2} \mathrm{Fe}_{14} \mathrm{~B}$ grains from each other [4-13]. For the best performance, the fraction of $\mathrm{Nd}_{2} \mathrm{Fe}_{14} \mathrm{~B} / \mathrm{Nd}_{2} \mathrm{Fe}_{14} \mathrm{~B}$ GBs covered by the Nd-rich phase has to be as high as possible. On the other hand, the total amount of Nd-rich phase has to be kept possibly low since the $\mathrm{Nd}$-rich phase is non-ferromagnetic and, therefore, decreases the overall $B$ value of a whole magnet. Usually, the Nd-rich phase in $\mathrm{Nd}_{2} \mathrm{Fe}_{14} \mathrm{~B} / \mathrm{Nd}_{2} \mathrm{Fe}_{14} \mathrm{~B}$ GBs and $\mathrm{GB}$ triple junctions (TJs) appears during the liquid-phase sintering of $\mathrm{Nd}_{2} \mathrm{Fe}_{14} \mathrm{~B}$ powder with REMs at about $1100^{\circ} \mathrm{C}$ followed by a definite heat treatment $[7,8,13]$. It is generally believed nowadays that this $\mathrm{Nd}$-rich phase is always formed by metallic $\mathrm{Nd}$ or several
Nd-rich binary, ternary or multicomponent compounds consisted of REMs, TMs and boron [5,13].

However, the commercial Nd-Fe-B-based permanent magnets contain not only REMs, TMs and boron. During the production, some oxygen is always present in the protective atmosphere, and the easily oxidizing REMs form the oxides. The oxides are almost inevitable in commercial magnets. Large (from several to tens of $\mu \mathrm{m}$ ) oxide particles in GB TJs are easily observed in the samples not only in our studies (see Fig. 1) but also in most published works [13-20]. Unfortunately, only few authors discussed the possible role of GB oxide layers in Nd-Fe-B-based permanent magnets [21-30]. Partially, it is because the experimental possibility for the reliable local measurements of oxygen content using electron energy loss spectroscopy (EELS) with simultaneous determination of oxide phase crystal structure by means of high-resolution TEM (HRTEM) is not always available. Recently, first studies were done where oxygen was detected in thin layers of Nd-rich GB phase by means of EELS technique $[22,23]$. The fastFourier transformation (FFT) of the micrographs obtained by the high-resolution transmission electron microscopy (HR TEM) also reveals the presence of GB layers with $\mathrm{Nd}_{2} \mathrm{O}_{3}$ structure [23-30].

\section{GB oxides in Nd-Fe-B-based alloys}

The oxides are almost inevitable in the Nd-Fe-B-based sintered permanent magnets [13-20]. In laboratory conditions, the special care is frequently taken to exclude the influence of oxygen [31]. These precautions are too 


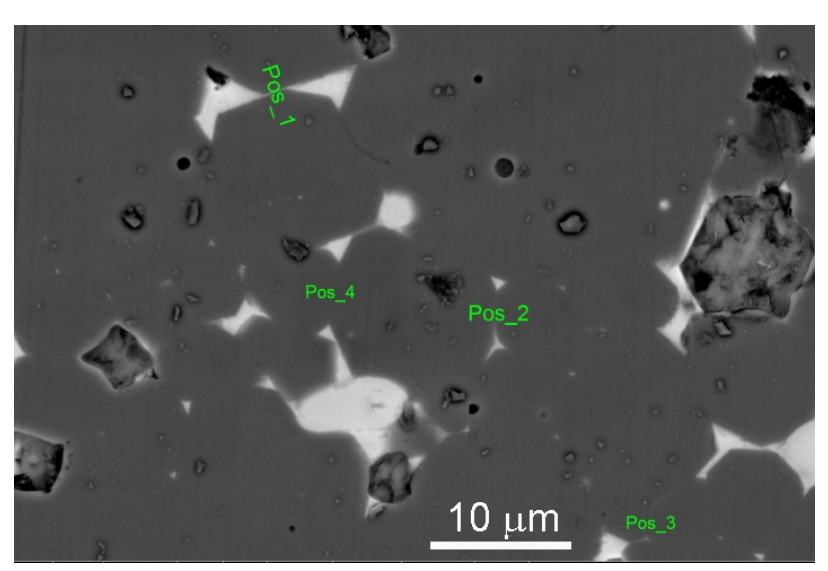

Fig. 1. SEM micrographs of commercial Nd-Fe-B-based sintered alloy. $\mathrm{Nd}_{2} \mathrm{Fe}_{14} \mathrm{~B}$ grains appear dark. Nd-rich GB and TJ layers appear bright. $\mathrm{Nd}_{2} \mathrm{O}_{3}$ particles appear dark-grey and faceted. Positions 1 to 4 mark the locations of thin GB wetting layers.

expensive in case of industrial production, and oxygen is usually present in the sintered Nd-Fe-B-based permanent magnets [32]. X-ray diffraction (XRD) data show that they contain at least few percent of $\mathrm{Nd}_{2} \mathrm{O}_{3}$ or $\mathrm{NdO}_{x}$ phases with cI80 and fcc lattice, respectively $[6,7,15,33,34]$. $\mathrm{Nd}_{2} \mathrm{O}_{3}$ phase can also have hP5 hexagonal structure (for the reference of the $\mathrm{Nd}$ and neodymium oxides crystal structure see Table 1). The metallic Nd phase can exist with fcc and double hcp (hP4) lattice. The oxide particles in $\mathrm{Nd}_{2} \mathrm{Fe}_{14} \mathrm{~B}$ grains TJs are clearly visible in SEM [5,6,13,14,16-19,35-37] and TEM $[6,7,14,17,27,28,38,39]$. In addition to the results obtained from XRD and electron diffraction, the EDS measurements also reveal the presence of oxygen in these non-metallic particles $[7,15,16,20,35-37,40]$. Thus, the bulk oxides are conventional in the sintered $\mathrm{Nd}-\mathrm{Fe}-\mathrm{B}$-based permanent magnets and the overall oxygen content is far from negligible.

It is generally accepted that thin GB layers of nonferromagnetic Nd-rich phase are responsible for the "magnetic isolation" or decoupling of $\mathrm{Nd}_{2} \mathrm{Fe}_{14} \mathrm{~B}$ grains from each other [4-13]. In turn, this magnetic isolation leads to high coercivity of the sintered $\mathrm{Nd}-\mathrm{Fe}-\mathrm{B}$-based permanent magnets $[5,6]$. The question is whether these magnetically isolating Nd-rich GB layers always consist of metallic (or intermetallic) phase or they can also contain oxides?

Usually, the composition of GB layers in Nd-Fe-B-based permanent magnets is measured by EDS in TEM and SEM $[6,41-43]$. In these measurements, the content of main metallic elements is mostly determined $[6,43]$, and only very seldom that of oxygen $[6,41,43]$. For example, the minima of iron and cobalt concentrations as well as maxima of oxygen, fluorine, neodymium and praseodymium concentrations were observed by EDS in the $\sim 4 \mathrm{~nm}$ thin GB area [43]. Unfortunately, the data for oxygen concentration obtained by EDX are not very reliable in comparison with the content of metallic elements due to the low atomic mass, low peakto-background ratio and EDX peaks overlapping. The EELS measurements of oxygen concentration are more accurate. However, only few works of this kind are available [22,23]. Zickler and co-authors observed $\mathrm{Nd}_{2} \mathrm{Fe}_{14} \mathrm{~B} / \mathrm{Nd}_{2} \mathrm{Fe}_{14} \mathrm{~B}$ GBs containing the 3-10 $\mathrm{nm}$ thin GB layers. EELS showed that these GB layers were depleted with $\mathrm{Fe}+\mathrm{Co}$ and enriched with $\mathrm{Pr}+\mathrm{Nd}$ and oxygen in comparison with bulk $\mathrm{Nd}_{2} \mathrm{Fe}_{14} \mathrm{~B}$ phase. Unfortunately, the analysis of phase composition of Pr-Nd-O-rich GB layers were lacking in the cited articles, as well as the evidence on $\mathrm{Nd}_{2} \mathrm{Fe}_{14} \mathrm{~B}$ phase magnetic decoupling.

Atom probe tomography was also applied to detect oxygen in $\mathrm{Nd}-\mathrm{Fe}-\mathrm{B}$ hard magnets $[6,44]$. The measured volume contained $\sim 5 \mathrm{~nm}$ thin GB layer between $\mathrm{Nd}_{2} \mathrm{Fe}_{14} \mathrm{~B}$ grains. The grains expectedly contained iron, neodymium, praseodymium, boron and they were oxygen free. Contrary, the GB layers were free of boron and iron, but revealed the peak of oxygen and $\mathrm{Nd}+\mathrm{Pr}$ mixture. Depending on the processing conditions, the GB phase was found to be either $\mathrm{Nd}_{6} \mathrm{Fe}_{13} \mathrm{Ga}$ intermetallic compound, amorphous or crystalline neodymium oxide with cI80 structure. The amorphous Nd-rich GB layers were also observed in Refs. [5,13,42]. In Ref. [39] it was shown that the GB layer phase composition depends on the content of trace alloying components.

In [34] the possible influence of GB phase on the magnetic properties of $\mathrm{Nd}-\mathrm{Fe}-\mathrm{B}$ alloys was analyzed based on the atomistic model and finite-element method simulation. The authors considered different GB phases, both metallic Nd (fcc and double hcp hP4) and neodymium oxides $\mathrm{Nd}_{2} \mathrm{O}_{3}$ (a-type, hP5 and c-type, cI80), and $\mathrm{NdO}$ (cF8). It was shown that some of these phases (namely, fcc $\mathrm{Nd}, \mathrm{Nd}_{2} \mathrm{O}_{3} \mathrm{cI} 80$ and $\mathrm{NdO} \mathrm{cF} 8$ ) have less detrimental effect on $\mathrm{Nd}_{2} \mathrm{Fe}_{14} \mathrm{~B}$ grains coercivity.

TEM and HREM studies in Nd-Fe-B-based sintered magnets revealed that GBs can contain thin layers of Nd-rich phase with $F m \overline{3} m$ or $P^{6_{3}} / m m c$ as well as $P^{6_{3}} / m m c, \operatorname{Im} \overline{3} m$ or I $a \overline{3}$ crystalline structure $[13,17,18,21,24-30]$. In first case such structure can be assigned to the conventional metallic Nd phase (see Table 1). In latter case the $P^{6_{3}} / m m c, \operatorname{Im} \overline{3} m$ or $I a \overline{3}$ crystalline structures are typical for the $\mathrm{Nd}_{2} \mathrm{O}_{3}$ oxide (see Table 1). In the addition of structural TEM and HREM data, the presence of elemental oxygen in the thin GB layers have been revealed by the EDS $[21,29,30]$ or atom probe tomography [13]. Moreover, in [29] the authors claim that "a certain amount of oxygen is an indispensable ingredient to achieve a high coercivity in Nd-Fe-B sintered magnets".

Table 1. Structural data for neodymium and oxide neodymium phases.

\begin{tabular}{|c|c|c|c|c|c|}
\hline ICSD \# & Space group symbol & Pearson symbol & Formula & Cell parameters & Ref. \\
\hline 100211 & $P^{6_{3}} / m m c$ & $\mathrm{hP5}$ & $\mathrm{Nd}_{2} \mathrm{O}_{3}$ & $a=3.947 c=6.277$ & {$[45]$} \\
\hline 100216 & $\mathrm{Im} \overline{3} m$ & $\mathrm{cI} 5$ & $\mathrm{Nd}_{2} \mathrm{O}_{3}$ & $a=4.41$ & {$[45]$} \\
\hline 191535 & $I a \overline{3}$ & $\mathrm{cI} 80$ & $\mathrm{Nd}_{2} \mathrm{O}_{3}$ & $a=11.08$ & {$[46]$} \\
\hline & $F m \overline{3} m$ & $\mathrm{cF} 8$ & $\mathrm{NdO}$ & $a=4.994$ & {$[46]$} \\
\hline 76591 & $F m \overline{3} m$ & $\mathrm{cF} 4$ & $\mathrm{Nd}$ & $a=4.917$ & {$[47]$} \\
\hline 9008508 & $P^{6_{3}} / m m c$ & $\mathrm{hP} 2$ & $\mathrm{Nd}$ & $a=3.657 c=5.9020$ & {$[48]$} \\
\hline 76592 & $P^{6_{3}} / m m c$ & $\mathrm{hP} 4$ & $\mathrm{Nd}$ & $a=3.6582 c=11.7966$ & {$[49]$} \\
\hline
\end{tabular}


Thus, summing up the published data one can see that the presence of neodymium oxide is a characteristic feature of Nd-Fe-B-based magnets.

\section{GB wetting phenomena in Nd-Fe-B-based alloys}

An important issue for the magnetic properties of $\mathrm{Nd}-\mathrm{Fe}$-B-based magnets is also the interplay between Nd-rich phase in TJs and $\mathrm{Nd}_{2} \mathrm{O}_{3}$ layers in GBs. The presence of thin films of Nd-rich phase (s) in the $\mathrm{Nd}_{2} \mathrm{Fe}_{14} \mathrm{~B} / \mathrm{Nd}_{2} \mathrm{Fe}_{14} \mathrm{~B}$ GBs is the special case of the more general phenomenon of intergranular thin films (IGFs) [50-67]. The IGFs can appear in equilibrium, non-equilibrium or steady-state structures [68-78]. In the majority of cases IGFs are tightly related to GB wetting, prewetting and premelting phase transformations (for review see $[61,62]$ and references therein). The transformation between complete wetting (CW, Figs. 2c, d, g and $3 \mathrm{a}$ ) and partial wetting (PW, Figs. $2 \mathrm{a}, \mathrm{b}, \mathrm{g}$ and $3 \mathrm{~b}$ ) of GBs was first predicted by Cahn [79], and Ebner and Saam [80] from the analysis of equilibrium in the region near the critical point of two-component phase diagram.

Recently an extremely interesting phenomenon of pseudopartial (or pseudoincomplete, or frustrated complete) GB wetting was predicted [81] and observed (see Figs. 2 e,f) [82]. This phase transition lies between the PW and $\mathrm{CW}$ and marked as PPW in the generic phase diagram proposed in [83] (Figs. $2 \mathrm{~g}$ and 3c) [84-89]. In case of PPW, the thin GB layer (i.e. IGF) can contact the droplets (or particles) of a second phase at large non-zero contact angle (Figs. $2 \mathrm{f}$ and $3 \mathrm{c}$ ) [89]. Such IGFs can be observed in the broad ranges of concentrations, temperature and/or pressure and drastically modify the properties of polycrystals. In contrast to the thick (usually several tens of nanometers) CW GBs, the PPW IGFs are only several nanometers thin and often difficult to be observed [87]. This kind of phase transitions can take place not only during the liquid-phase sintering or annealing, but also during the mechanical treatment of the material [86, $90-93]$.

The transition from $\mathrm{PW}$ to $\mathrm{CW}$ of $\mathrm{Nd}_{2} \mathrm{Fe}_{14} \mathrm{~B} / \mathrm{Nd}_{2} \mathrm{Fe}_{14} \mathrm{~B}$ $\mathrm{GBs}$ in ternary Nd-Fe-B alloys takes place according to our data $[94,95]$. At $700^{\circ} \mathrm{C}$ the fraction of completely wetted GBs is zero and it increases up to almost $100 \%$ at $1200^{\circ} \mathrm{C}$ (Fig. 3). The analysis of published data for the microstructure of liquid-phase sintered Nd-Fe-B-based multicomponent alloys shows that the amount of GBs with zero contact angle in these alloys is far below $100 \%$ [95]. In other words, during the typical liquid-phase sintering at $\sim 1100^{\circ} \mathrm{C}$ only low GB fraction is completely wetted. It means that the formation of thick Nd-rich phase IGFs during liquid-phase sintering by $\mathrm{PW}-\mathrm{CW}$ phase transition is not the main reason for the appearance of Nd-rich GB phase.

Later it has been observed that PPW GBs also exist in Nd-Fe-B alloys [88] (Fig. 4) and make a significant fraction of the wetted GBs. We suppose that the PPW is responsible for the formation of magnetically separating Nd-rich IGFs for $\mathrm{Nd}_{2} \mathrm{Fe}_{14} \mathrm{~B}$ grains [96]. This concerns both metallic $\mathrm{Nd}$ or $\mathrm{Nd}$-rich intermetallic compounds as well as Nd-oxide GB layers.

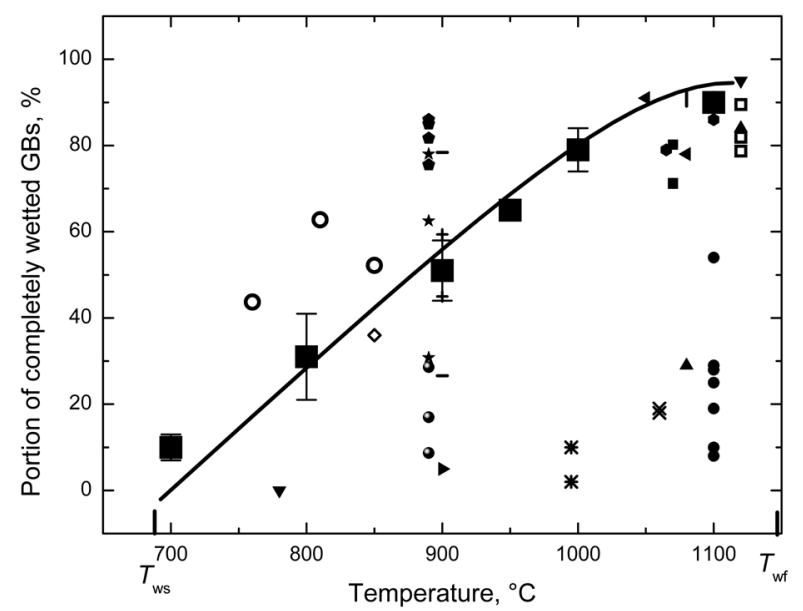

Fig. 3. Temperature dependence for the fraction of $\mathrm{Fe}_{14} \mathrm{Nd}_{2} \mathrm{~B}$ GBs completely wetted by the Nd-rich phase (large full squares, thick line) [94]. $T_{\mathrm{ws}}=690 \pm 10^{\circ} \mathrm{C}$ and $T_{\mathrm{wf}}=1150 \pm 10^{\circ} \mathrm{C}$ are, respectively, the temperatures of the beginning and end of the GB wetting phase transition of $\mathrm{Fe}_{14} \mathrm{Nd}_{2} \mathrm{~B}$ GBs by the Nd-rich liquid phase. The large filled squares represent the results obtained in [94]. The small symbols are the results obtained by analyzing data from the literature for liquid-state sintering samples [94].

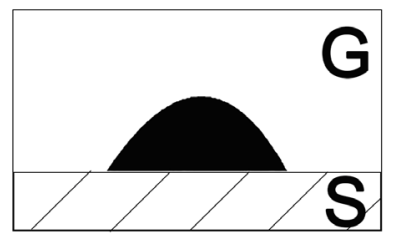

a

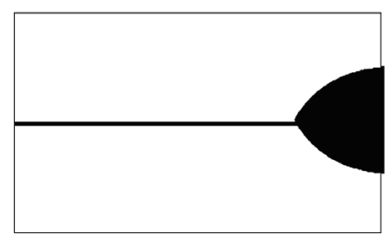

b

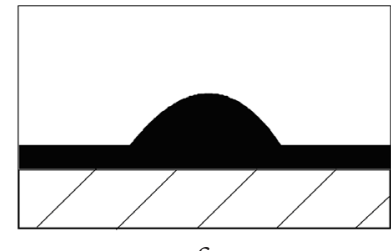

$\mathrm{C}$

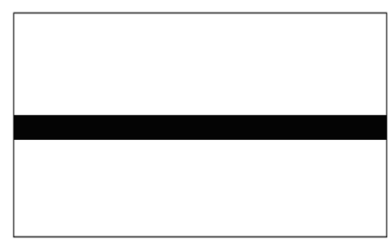

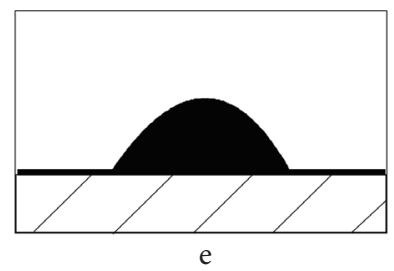

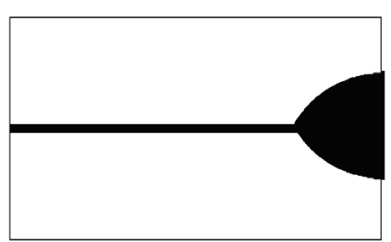

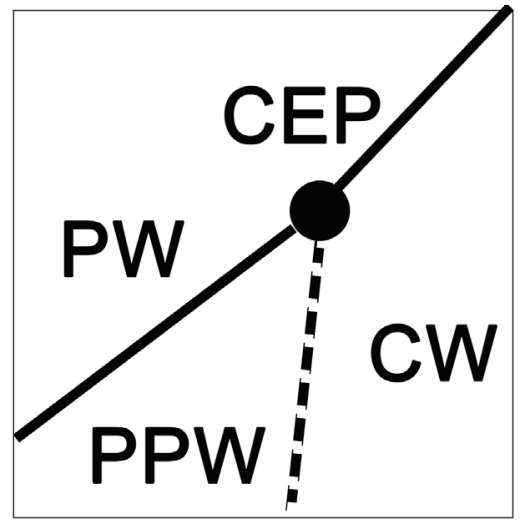

g

Fig. 2. The schemes for the wetting phase transitions of free surface and GB. partial surface wetting, $L-$ liquid phase, $S-$ solid phase, G - gas phase (a); partial GB wetting (b); complete surface wetting (c); complete GB wetting (d); pseudopartial surface wetting (e); pseudopartial GB wetting (f); generic wetting phase diagram [80, 81], PW - partial wetting, CW - complete wetting, PPW - pseudopartial wetting, CEP - critical end point, thick lines mark the discontinuous (first order) wetting transition, thin line mark the continuous (second order) wetting transition (g). 


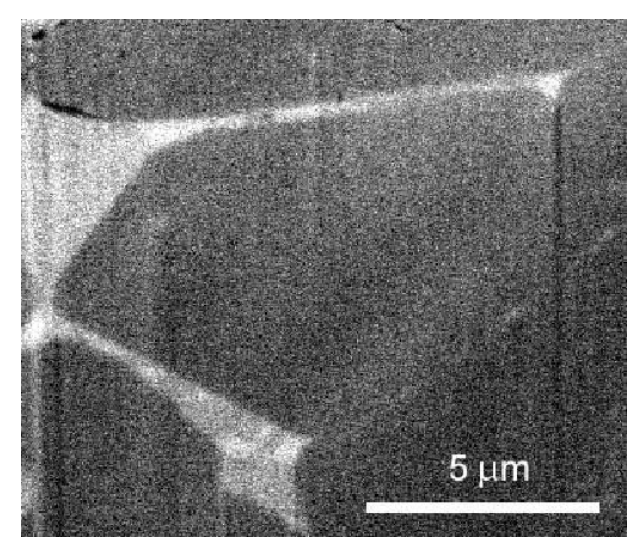

a

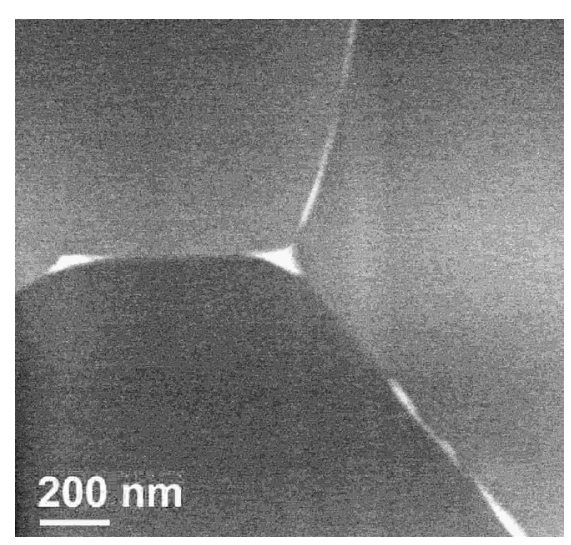

$\mathrm{b}$

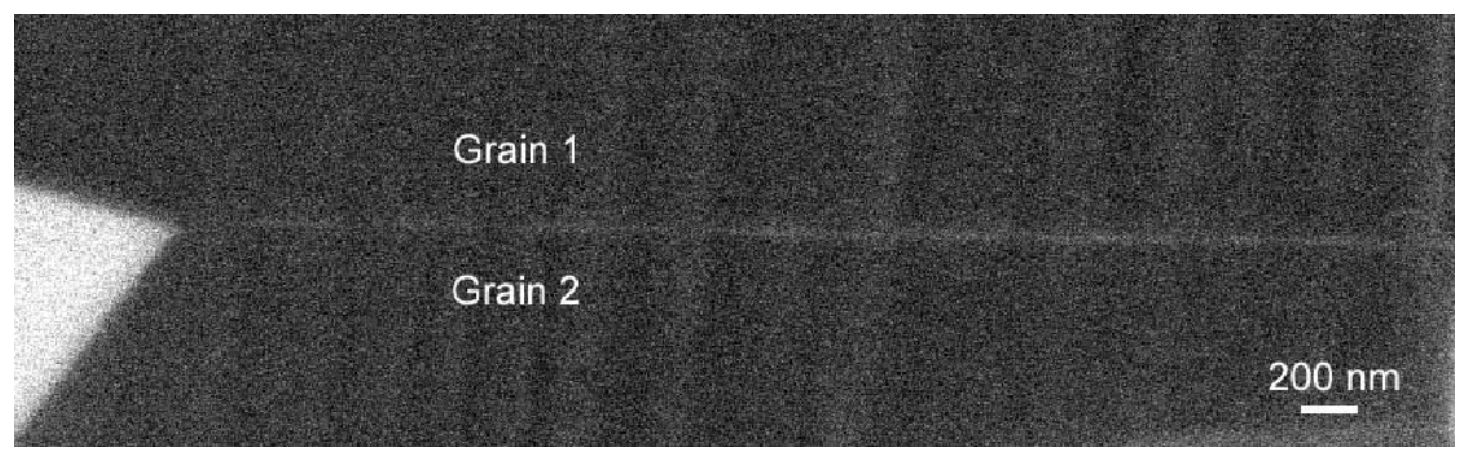

C

Fig. 4. SEM micrographs of commercial Nd-Fe-B-based sintered alloy. $\mathrm{Nd}_{2} \mathrm{Fe}_{14} \mathrm{~B}$ grains appear dark. Nd-rich GB and TJ layers appear bright. Complete GB wetting by the Nd-rich phase (a). Incomplete (partial) GB wetting (b). Pseudo-incomplete (pseudo-partial) GB wetting (c).

\section{Conclusions}

GB layers of Nd-rich phase play crucial role in the Nd-Fe-B-based permanent magnets. A certain fraction of these Nd-rich GB layers contains oxygen. The crystalline lattice of these GB layers corresponds to that of the $\mathrm{Nd}_{2} \mathrm{O}_{3}$ and not to those of metallic Nd or Nd-rich intermetallic compounds. The Nd-oxide GB layers prevent the migration of domain walls from one $\mathrm{Nd}_{2} \mathrm{Fe}_{14} \mathrm{~B}$ grain to another during magnetization and de magnetization. Thus, the GB oxide layers, similar to the "conventional" Nd-rich metallic ones, can ensure the magnetic isolation between $\mathrm{Nd}_{2} \mathrm{Fe}_{14} \mathrm{~B}$ grains needed for high coercivity. Therefore, the GB oxide layers can be used for further development of Nd-Fe-B-based permanent magnets in combination with GB layers containing the metallic $\mathrm{Nd}$ or intermetallic compounds. The morphology of intergranular phases is controlled by the GB wetting phase transitions.

Acknowledgements. Financial support from the state tasks of Institute of Solid State Physics and Chernogolovka Scientific Center of RAS and the Russian Foundation for Basic Research (grant 18-03-00284) is gratefully acknowledged.

\section{References}

1. M. Sagawa, S. Fujimura, N. Togawa et al. J. Appl. Phys. 55, 2083 (1984). Crossref
2. J.J. Croat, J.F. Herbst, R. W. Lee et al. J. Appl. Phys. 55, 2078 (1984). Crossref

3. G. C. Hadjipanayis, R. C. Hazelton, K. R. Lawless. J. Appl. Phys. 55, 2073 (1984). Crossref

4. T. Helbig, K. Loewe, S. Sawatzki et al. Acta Mater. 127, 498 (2017). Crossref

5. K. Hono, H. Sepehri-Amin. Scripta Mater. 67, 530 (2012). Crossref

6. T. T. Sasaki, Y. Takada, H. Okazaki, et al. J. Alloys Compd. 790, 750 (2019). Crossref

7. T.T. Sasaki, T. Ohkubo, Y. Takada et al. Scripta Mater. 113, 218 (2016). Crossref

8. K. H. J. Buschow. Magnetism and processing of permanent magnet materials. In: Handbook of Magnetic Materials. Chichester, UK, John Wiley \& Sons (1997) pp. 463 - 593.

9. H. Kronmüller, R. Fischer, M. Seeger et al. J. Phys. D. Appl. Phys. 29, 2274 (1996). Crossref

10. W. Rodewald. Rare-earth Transition-metal Magnets. In: Handbook of Magnetism and Advanced Magnetic Materials. Chichester, UK, John Wiley \& Sons (2007). Crossref

11. M. Seeger, J. Bauer, H. Kronmüller et al. J. Magn. Magn. Mater. 138, 294 (1994). Crossref

12. J. Bernardi, J. Fidler, M. Seeger et al. IEEE Trans. Magn. 29, 2773 (1993). Crossref

13. H. Sepehri-Amin, T. Ohkubo, T. Shima et al. Acta Mater. 60, 819 (2012). Crossref

14. W. F. Li, T. Ohkubo, K. Hono, M. Sagawa. J. Magn. Magn. Mater. 321, 1100 (2009). $\underline{\text { Crossref }}$ 
15. H. Okazaki, D. Billington, N. Tsuji et al. Acta Mater. 181, 530 (2019). Crossref

16. Z. Mural, L. Kollo, M. Xia et al. J. Magn. Magn. Mater. 429, 23 (2017). Crossref

17. K. Lu, X. Bao, G. Chen et al. J. Magn. Magn. Mater. 477, 237 (2019). Crossref

18. W. Mo, L. Zhang, Q. Liu et al. Scripta Mater. 59, 179 (2008). Crossref

19. Y. Shinba, T. J. Konno, K. Ishikawa et al. J. Appl. Phys. 97, 053504 (2005). Crossref

20. E. Isotahdon, E. Huttunen-Saarivirta, V.-T. Kuokkala. J. Alloys Compd. 692, 190 (2017). Crossref

21. T. G. Woodcock, Y. Zhang, G. Hrkac et al. Scripta Mater. 67, 536 (2012). Crossref

22. G. A. Zickler, J. Fidler, J. Bernardi et al. Adv. Mater. Sci. Eng. 2017, 6412042 (2017).

23. G. A. Zickler, J. Fidler. Adv. Mater. Sci. Eng. 2017, 1461835 (2017).

24. T.H. Kim, S. R. Lee, M.W. Lee et al. Acta Mater. 66, 12 (2014). Crossref

25. Y. Zhang, T. Ma, J. Jin et al. Acta Mater. 128, 22 (2017). Crossref

26. T.H. Kim, S. R. Lee, K. H. Bae et al. Acta Mater. 133, 200 (2017). Crossref

27. T. Ma, B. Wu, Y. Zhang et al. J. Alloys Compd. 721, 1 (2017) Crossref

28. T. Fukagawa, S. Hirosawa. J. Appl. Phys. 104, 013911 (2008). Crossref

29. T. Fukagawa, S. Hirosawa, T. Ohkubo et al. J. Appl. Phys. 105, 07 A724 (2009). Crossref

30. D. W. Park, T.H. Kim, S. R. Lee et al. J. Appl. Phys. 107, 09A737 (2010). Crossref

31. H. Sepehri-Amin, Y. Une, T. Ohkubo et al. Scripta Mater. 65, 396 (2011). Crossref

32. X.D. Xu, T.T. Sasaki, J. N. Li et al. Acta Mater. 156, 146 (2018). Crossref

33. T.-H. Kim, S.-R. Lee, S. Namkumg et al. J. Alloys Compd. 537, 261 (2012). Crossref

34. G. Hrkac, T.G. Woodcock, K.T. Butler, et al. Scripta Mater. 70, 35 (2014). Crossref

35. F. Yang, L. Guo, P. Li et al. J. Magn. Magn. Mater. 429, 117 (2017). Crossref

36. Y. Wang, J. Ahn, D. Kim et al. J. Magn. Magn. Mater. 439, 91 (2017). Crossref

37. F. Chen, T. Zhang, W. Zhang et al. J. Magn. Magn. Mater. 465, 392 (2018). Crossref

38. G. Hrkac, K. Butler, T. G. Woodcock et al. JOM. 66, 1138 (2014). Crossref

39. T.-H. Kim, S.-R. Lee, J. Woo Kim et al. J. Appl. Phys. 115, 17A770 (2014). Crossref

40. M.-W. Lee, K.-H. Bae, S.-R. Lee et al. Arch. Metall. Mater. 62, 1263 (2017). Crossref

41. G. Ding, S. Guo, L. Chen et al. J. Alloys Compd. 735, 795 (2018). Crossref

42. H. Sepehri-Amin, T. Ohkubo, S. Nagashima et al. Acta Mater. 61, 6622 (2013). Crossref

43. F. Bittner, T. G. Woodcock, L. Schultz et al. J. Magn. Magn. Mater. 426, 698 (2017). $\underline{\text { Crossref }}$

44. K. Niitsu, A. Sato, T. T. Sasaki et al. J. Alloys Compd. 752, 220 (2018). $\underline{\text { Crossref }}$
45. P. Aldebert, J. P. Traverse. Mater. Res. Bull. 14, 303 (1979). Crossref

46. C. Artini, M. Pani, J. R. Plaisier et al. Solid State Ionics. 257, 38 (2014). Crossref

47. G. J. Piermarini, C.E. Weir. Science. 144, 69 (1964). Crossref

48. R. W. G. Wyckoff, Crystal Structures. Vol. 1. Interscience Publishers, New York (1963).

49. C. Lundin, A. Yamamoto, J. Nachman. Acta Metall. 13, 149 (1965). Crossref

50. B. B. Straumal, A. A. Mazilkin, B. Baretzky. Curr. Opin. Solid State Mater. Sci. 20, 247 (2016). Crossref

51. J. G. Dash, H. Fu, J. S. Wettlaufer. Reports Prog. Phys. 58, 115 (1995). Crossref

52. M. Kuzmina, M. Herbig, D. Ponge et al. Science. 349, 1080 (2015). Crossref

53. P.R. Cantwell, M. Tang, S. J. Dillon et al. Acta Mater. 62, 1 (2014). Crossref

54. W. D. Kaplan, D. Chatain, P. Wynblatt et al. J. Mater. Sci. 48, 5681 (2013). Crossref

55. P. R. Bueno, J. A. Varela, E. Longo. J. Eur. Ceram. Soc. 28, 505 (2008). Crossref

56. J. Luo, Y.-M. Chiang, R. M. Cannon. Langmuir. 21, 7358 (2005). Crossref

57. J. Luo, M. Tang, R. M. Cannon et al. Mater. Sci. Eng. A. 422, 19 (2006). Crossref

58. D. R. Clarke. J. Am. Ceram. Soc. 70, 15 (1987). Crossref

59. J. Luo. Crit. Rev. Solid State Mater. Sci. 32, 67 (2007). Crossref

60. J. Luo, Y.-M. Chiang. Annu. Rev. Mater. Res. 38, 227 (2008). rossref

61. A. Subramaniam, C. T. Koch, R. M. Cannon et al. Mater. Sci. Eng. A. 422, 3 (2006). Crossref

62. I. MacLaren. Ultramicroscopy. 99, 103 (2004). Crossref

63. S. J. Dillon, M. Tang, W.C. Carter et al. Acta Mater. 55, 6208 (2007). Crossref

64. M.P. Harmer. J. Am. Ceram. Soc. 93, 301 (2010). Crossref 65. S. G. Protasova, B. B. Straumal, A.A. Mazilkin et al. J. Mater. Sci. 49, 4490 (2014). Crossref

66. N. Zhou, J. Luo. Acta Mater. 91, 202 (2015). Crossref

67. J. Luo, H. Cheng, K. M. Asl et al. Science. 333, 1730 (2011). Crossref

68. E. L. Maksimova, L. S. Shvindlerman, B. B. Straumal. Acta Metall. 36, 1573 (1988). Crossref

69. R. Valiev, M.Y. Murashkin, B. B. Straumal. Mater. Sci. Forum. 633-634, 321 (2009). Crossref

70. L. S. Chang, B. B. Straumal, E. Rabkin et al. J. Phase Equilibria. 18, 128 (1997). Crossref

71. N. Q. Chinh, T. Csanádi, J. Gubicza et al. Mater. Sci. Forum. $667-669,677$ (2010). Crossref

72. O. I. Noskovich, E.I. Rabkin, V.N. Semenov et al. Acta Metall. Mater. 39, 3091 (1991). $\underline{\text { Crossref }}$

73. B. Straumal, O. Noskovich, V. Semenov et al. Acta Metall. Mater. 40, 795 (1992). Crossref

74. W. Rheinheimer, M. J. Hoffmann. Scripta Mater. 101, 68 (2015). Crossref

75. E. I. Rabkin, L.S. Shvindlerman, B.B. Straumal. Int. J. Mod. Phys. B. 5, 2989 (1991). Crossref

76. A.K. Lawrence, A. Kundu, M.P. Harmer et al. J.Am. Ceram. Soc. 98, 1347 (2015). Crossref 
77. L. S. Chang, E. Rabkin, B. B. Straumal et al. Defect Diff. Forum. 156, 135 (1998). Crossref

78. L.-S. Chang, E. Rabkin, B. Straumal et al. Scripta mater. 37, 729 (1997). Crossref

79. J. W. Cahn. J. Chem. Phys. 66, 3667 (1977). Crossref

80. C. Ebner, W.F. Saam. Phys. Rev. Lett. 38, 1486 (1977). Crossref

81. F. Brochard-Wyart, J.M. Di Meglio, D. Quere et al. Langmuir. 7, 335 (1991). Crossref

82. D. Bonn, J. Eggers, J. Indekeu et al. Rev. Mod. Phys. 81, 739 (2009). Crossref

83. S. Rafaï, D. Bonn, E. Bertrand et al. Phys. Rev. Lett. 92, 245701 (2004). Crossref

84. J. Moon, P. Wynblatt, S. Garoff et al. Surf. Sci. 559, 149 (2004). Crossref

85. B. B. Straumal, X. Sauvage, B. Baretzky et al. Scripta Mater. 70, 59 (2014). Crossref

86. B. B. Straumal, A.A. Mazilkin, X. Sauvage et al. Russ. J. Non-Ferrous Met. 56, 44 (2015). Crossref

87. B. B. Straumal, I. Konyashin, B. Ries et al. Mater. Lett. 147,
105 (2015). Crossref

88. B. B. Straumal, A.A. Mazilkin, S. G. Protasova et al. Rev. Adv. Mater. Sci. 38, 17 (2014).

89. B. B. Straumal, A. O. Rodin, A. E. Shotanov et al. Defect Diffus. Forum. 333, 175 (2013). $\underline{\text { Crossref }}$

90. B. B. Straumal, A. A. Mazilkin, S. G. Protasova et al. Mater. Lett. 161, 735 (2015). Crossref

91. X. Sauvage, M.Y. Murashkin, B. B. Straumal et al. Adv. Eng. Mater. 17, 1821 (2015). Crossref

92. N. Q. Chinh, R. Z. Valiev, X. Sauvage et al. Adv. Eng. Mater. 16, 1000 (2014). Crossref

93. B. B. Straumal, A.A. Mazilkin, S. G. Protasova et al. J. Mater. Eng. Perform. 25, 3303 (2016). Crossref

94. B. B. Straumal, Y. O. Kucheev, I. L. Yatskovskaya et al. J. Mater. Sci. 47, 8352 (2012). $\underline{\text { Crossref }}$

95. Y.O. Kucheev, A.B. Straumal, I. V. Mogil'nikova et al. Russ. J. Non-Ferrous Met. 53, 450 (2012). Crossref

96. A. Mazilkin, B. Straumal, S. Protasova et al. Defect Diffus. Forum 380, 173 (2017). Crossref 